\title{
A randomised controlled trial of cognitive behaviour therapy for psychosis in a routine clinical service
}

Article

Accepted Version

Peters, E., Landau, S., McCrone, P., Cooke, M., Fisher, P., Steel, C., Evans, R., Carswell, K., Dawson, K., Williams, S., Howard, A. and Kuipers, E. (2010) A randomised controlled trial of cognitive behaviour therapy for psychosis in a routine clinical service. Acta Psychiatrica Scandinavica, 122 (4). pp. 302-318. ISSN 0001-690X doi: https://doi.org/10.1111/j.16000447.2010.01572.x Available at https://centaur.reading.ac.uk/8001/

It is advisable to refer to the publisher's version if you intend to cite from the work. See Guidance on citing.

Published version at: http://dx.doi.org/10.1111/j.1600-0447.2010.01572.x

To link to this article DOI: http://dx.doi.org/10.1111/j.1600-0447.2010.01572.x

Publisher: Wiley-Blackwell

All outputs in CentAUR are protected by Intellectual Property Rights law, including copyright law. Copyright and IPR is retained by the creators or other copyright holders. Terms and conditions for use of this material are defined in the End User Agreement. 


\section{CentAUR}

Central Archive at the University of Reading

Reading's research outputs online 


\title{
A Randomised Controlled Trial of Cognitive Behaviour Therapy for Psychosis in a routine clinical service
}

\section{Short title for running head: Cognitive Behaviour Therapy for Psychosis (CBTp) in an outpatient service}

\begin{abstract}
Emmanuelle Peters ${ }^{1,5}, *$, Sabine Landau ${ }^{2}$, Paul McCrone ${ }^{3}$, Michael Cooke ${ }^{1}$, Peter Fisher ${ }^{1}$, Craig Steel $^{1}$, Ruth Evans ${ }^{1}$, Ken Carswell ${ }^{1}$, Katherine Dawson ${ }^{1}$, Sally Williams ${ }^{1}$, Alan Howard $^{4}$, \& Elizabeth Kuipers ${ }^{1,5}$
\end{abstract}

\footnotetext{
${ }^{1}$ Department of Psychology, King's College London, Institute of Psychiatry, London, U.K. ${ }^{2}$ Department of Biostatistics, King's College London, Institute of Psychiatry, London, U.K. ${ }^{3}$ Department of Health Services Research, King's College London, Institute of Psychiatry, London, U.K.

${ }^{4}$ National Psychosis Service, South London and Maudsley NHS Foundation Trust, London, U.K.

${ }^{5}$ NIHR Biomedical Research Centre for Mental Health, South London and Maudsley NHS Foundation Trust, London, U.K.
}

*Corresponding author. Address: PO77, Psychology Department, King's College London, Institute of Psychiatry, De Crespigny Park, London SE5 8AF, UK; e-mail:

emmanuelle.peters@kcl.ac.uk; Tel: +44 (0) 207848 0347; Fax: +44 (0) 2078485006

Revised version, submitted to Acta Psychiatrica October 09 


\section{Abstract}

Objective: To evaluate CBTp delivered by non-expert therapists, using CBT relevant measures.

Methods: Participants $(\mathrm{N}=74)$ were randomised into immediate therapy or waiting list control groups. The therapy group was offered six months of therapy and followed up three months later. The waiting list group received therapy after waiting nine months (becoming the delayed therapy group).

Results: Depression improved in the combined therapy group at both the end of therapy and follow-up. Other significant effects were found in only one of the two therapy groups (positive symptoms; cognitive flexibility; uncontrollability of thoughts) or one of the two timepoints (end of therapy: PANSS general symptoms, anxiety, suicidal ideation, social functioning, resistance to voices; follow-up: power beliefs about voices, negative symptoms). There was no difference in costs between the groups.

Conclusions: The only robust improvement was in depression. Nevertheless, there were further encouraging but modest improvements in both emotional and cognitive variables, in addition to psychotic symptoms.

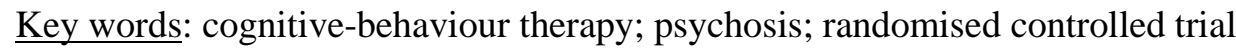

\begin{tabular}{|l|l|}
\hline Significant outcomes & $\begin{array}{l}\text { CBTp is effective in reducing depression in } \\
\text { distressed, medication-resistant individuals } \\
\text { with psychosis }\end{array}$ \\
\hline & $\begin{array}{l}\text { CBTp can be effective when delivered by } \\
\text { non-expert, but supervised, CBT therapists in } \\
\text { an NHS setting }\end{array}$ \\
\hline Limitations & $\begin{array}{l}\text { CBTp may be effective in different areas of } \\
\text { functioning, but improvements may not be } \\
\text { consistent across individuals or last beyond } \\
\text { the end of therapy }\end{array}$ \\
\hline & $\begin{array}{l}\text { The study may have been underpowered due } \\
\text { to drop-outs and missing data }\end{array}$ \\
\hline & $\begin{array}{l}\text { Neither patients nor assessors were blind to } \\
\text { allocated group }\end{array}$ \\
\hline & $\begin{array}{l}\text { The therapy groups could not be combined } \\
\text { for all outcomes, leading to different } \\
\text { outcomes being powered unevenly }\end{array}$ \\
\hline
\end{tabular}




\section{Background}

A number of randomised-controlled trials (RCTs) have established that cognitivebehaviour therapy for psychosis (CBTp) can be efficacious ${ }^{1}$. Several manuals ${ }^{2,3}$ are available which describe in detail the methods used. Efficacy is clearest for the medication-resistant group $^{4,5}$, and approximately fifty percent of such patients who undergo therapy can be expected to benefit ${ }^{6}$. This kind of therapy is highly acceptable to patients ${ }^{7}$, and studies have showed a continued improvement even after therapy is terminated ${ }^{8}$. This body of work has culminated in the British National Institute for Health and Clinical Excellence (NICE) guidelines, and the recent update, ${ }^{9}$ recommending that CBTp should be offered as an adjunctive treatment to medication to all individuals with psychosis.

Previous trials have used outcome measures of symptom change, such as the Positive and Negative Symptom Scale $\left(\mathrm{PANSS}^{10}\right)$, the Brief Psychiatric Rating Scale $\left(\mathrm{BPRS}^{11}\right)$, or the Comprehensive Psychiatric Rating Scale $\left(\mathrm{CPRS}^{12}\right)$, chosen to be compatible with those used in medication outcome studies ${ }^{13}$ While such an approach is in line with recent views that psychological and drug therapies achieve therapeutic gains through similar pathways ${ }^{14,15}$, nevertheless key researchers in this area have advocated that CBTp is not a quasi-neuroleptic, and that main outcome measures should relate to distress and/or behaviour rather than symptom change ${ }^{16}$. Indeed, CBTp manuals stipulate that distress and disability, rather than symptom change, should be addressed ${ }^{2}$. Measures such as the PANSS are relatively poor at measuring distress ${ }^{17}$, and are therefore not the most suitable outcome measures for CBTp trials. More recent studies show that effect sizes in symptom change on the PANSS are modest at best ${ }^{1}$, and CBTp made no impact on relapse rates in a recent methodologically highly rigorous $\mathrm{RCT}^{18}$. In contrast, the largest effect size of all the CBTp trials so far (1.1) was reported in the one study ${ }^{19}$ that used a more targeted and psychologically meaningful outcome measure (compliance with voices).

It is therefore timely to consider how we measure outcomes in CBTp. One strategy is to carry out efficacy trials in selected samples for specific therapeutic procedures. This was 
demonstrated by Trower et al ${ }^{19}$ who targeted compliance behaviour in individuals with command hallucinations, and Fowler et $\mathrm{al}^{20}$ who targeted activity levels in an early psychosis group with poor social functioning. Another is to conduct effectiveness trials with an armoury of outcome measures to encompass the wide range of problems encountered in routine psychological services for individuals with psychosis. For instance, service users often report that symptoms can be less debilitating than other aspects of living with a psychotic disorder, such as social exclusion and stigma ${ }^{21}$, emotional problems and difficulties with relationships ${ }^{22}$. CBTp manuals emphasise that an individualised formulation approach is central to CBTp, and as such therapy goals vary widely between patients. Therefore it is theoretically appropriate to use a wider range of outcome measures than just psychotic symptom change.

In addition, few of the published trials have been set within routine clinical services. Most trials to date have either used expert therapists ${ }^{4}$, or implemented rigorous training procedures for their therapists with frequent supervision ${ }^{18,23}$. The therapy has often been delivered within research settings, for the duration of the trial only. Strict suitability criteria meant that patients have been highly selected. One exception is the effectiveness trial reported by Farhall et $\mathrm{al}^{24}$, which targeted a prospectively recruited representative sample of patients as they entered a community mental health service. However, similarly to Garety et al ${ }^{18}$, patients entered the trial following an inpatient admission or exacerbation of symptoms, and both the CBTp and control groups improved significantly on presence of psychotic symptoms.

\section{Aims of the study}

The present trial aimed to evaluate CBTp in an outpatient clinic with non-expert, but supervised, clinicians, and widened the primary outcomes to include CBT relevant measures in addition to symptom severity and insight. CBTp relevant measures were identified as (i) emotional problems, suicidal ideation and self-esteem; (ii) general functioning; (iii) beliefs about voices and the controllability of thoughts; (iv) cognitive flexibility and executive functioning. This trial also included an economic evaluation. 


\section{Method}

\section{$\underline{\text { Design \& procedures }}$}

Participants were recruited from referrals to the Psychological Interventions Clinic for Outpatients with Psychosis (PICuP), based in the South London and Maudsley Foundation NHS Trust (SLaM) in the UK.

A waiting-list control design was followed, which is a type of design increasingly being used in the literature ${ }^{25.26}$. Patients were randomised to either the waiting list control group (treatment as usual; TAU) or to immediate CBTp by being entered into a computerised randomisation programme written by the statistician. Patients receiving TAU were also given therapy after having waited nine months in the waiting list group, becoming the delayed therapy group. A waiting-list control design, including a delayed therapy TAU group, was decided on before the trial started for several reasons: (i) for ethical considerations (to allow everyone referred to the clinic access to treatment); (ii) to maximise referral rates; (iii) to minimise drop-outs; and (iv) to increase the power of our analyses. Medication dosages (initially and during the ensuing 18 months of the trial) were left to the decision of the treating psychiatrist, within the British National Formulary Guidelines.

Assessments were carried out by five independent research workers (RE, PF, MC, $\mathrm{KC}$, and $\mathrm{KD}$ ) who were not involved in the therapy. There were insufficient resources to keep assessors blind to treatment condition, but they were all trained in the use of the assessment measures.

\section{$\underline{\text { Assessments }}$}

Patients were assessed independently at four time points: at baseline, three months into therapy (not reported here other than for service use and costs), at the end of therapy (six months after baseline), and at a three months follow-up after the end of therapy (nine months after baseline). The delayed therapy group was assessed at three further time points i.e., three months into therapy (12 months after baseline, not reported here), at the end of therapy (15 
months after baseline), and at a three months follow-up after the end of therapy (18 months after baseline). A wide range of assessments was administered to account for the fact that CBTp targets different problems for different individuals, depending on the individualised formulation and the person's goals for therapy. Areas assessed, based on potential target problems identified in Fowler et $\mathrm{al}^{2}$, included psychotic symptoms, emotional problems, functioning (social and cognitive), beliefs about symptoms, and insight. An economic evaluation was also carried out. The order of presentation of assessment measures was counterbalanced across participants. The same order of presentation was kept for each participant at each time-point, as far as it was possible.

(i) Psychotic Symptom measures:

The Structured Clinical Interview for the Positive and Negative Syndrome Scale $\left(\right.$ PANSS $^{10}$ ) was used to be consistent with other CBTp trials. Each item is rated by the assessor on a severity scale ranging from 1 (absence of psychopathology) to 7 (extremely severe). Three scores are derived: Positive Symptom Scores (possible range of scores: 7-49); Negative Symptom Scores (possible range of scores: 7-49); General Symptom Scores (possible range of scores: 16-112).

(ii) Psychological measures of psychotic symptoms:

Beliefs About Voices Questionnaire-Revised $\left(B A V Q-R^{27}\right)$ :

This 35 item self-report questionnaire measures beliefs about, and emotional and behavioural responses to, voices. Each item is rated on a 4-point scale ranging from 0 (disagree) to 3 (strongly agree). The most relevant subscales for CBTp consist of 'omnipotence' (e.g. 'My voice is very powerful'), and 'malevolence' (e.g. 'My voice is persecuting me for no good reason') beliefs (both six items with potential ranges of score 018), and 'resistance' (four items for emotion: e.g. 'My voice frightens me' and five items for behaviour: e.g. 'When I hear my voice usually I tell it to leave me alone'; possible range of scores: 0-27). The remaining two subscales ('benevolence' beliefs, and 'engagement' with voices) were not included to reduce the number of analyses.

Meta-cognitions Questionnaire $\left(M C Q^{28}\right)$ : 
This scale measures meta-cognitive beliefs and processes, and was included because of reports that psychotic patients score higher on this measure ${ }^{29}$. Only one of the five subscales was used, namely the "negative beliefs about the controllability of thoughts and corresponding danger" (16 items: e.g. 'I find it difficult to control my thoughts' and 'I worry about my thoughts'). Items are scored from 1 (do not agree) to 4 (agree very much), with a possible range of scores of 16-64.

\section{(iii) Emotional problems}

Other psychological problems were assessed using the Beck Depression Inventory $\left(\mathrm{BDI}-\mathrm{II}^{30}\right.$; possible range of scores: $\left.0-63\right)$, the Beck Anxiety Inventory $\left(\mathrm{BAI}^{32}\right.$; possible range of scores: 0-63) and the Beck Suicidal Ideation Scale (BSI ${ }^{32}$; possible range of scores: 0-42). Higher scores represent more severe pathology on the three Beck scales. Self-esteem was measured using the Rosenberg Self-Esteem Scale ${ }^{33}$. The possible range of scores is 10-40, with higher scores indicating poorer self-esteem.

\section{(iv) Social and occupational functioning}

The Social and Occupational Functioning Assessment Scale $\left(\mathrm{SOFAS}^{34}\right.$; possible range of scores: 0-100, with higher scores representing better functioning), was completed by both the independent assessor, and by the patient's care coordinator, to ascertain social functioning. Ratings were averaged when there were two scores available.

In addition, the number of days spent in hospital in the nine months following randomisation was obtained from clinical notes for the TAU and immediate therapy groups.

(v) Cognitive functioning:

Cognitive functioning was assessed using the Brixton and Hayling Sentence Completion Tests ${ }^{35}$ (possible range of scores for both tests: 1-10, with higher scores representing better functioning) for executive functioning and cognitive flexibility respectively. The Quick Test ${ }^{36}$ was used to obtain a measure of verbal I.Q. at the baseline assessment.

(vi) Insight: 
Insight was measured using the self-report Insight Scale $\left(\mathrm{IS}^{37}\right)$, which measures three dimensions of insight: 'awareness of illness', 'awareness of symptoms', and 'awareness of the need for treatment'. Item 4 ('My stay in hospital is necessary') was excluded because all participants were outpatients. The remaining items from the 'awareness of need for treatment' dimension were used to calculate a score for this subscale with equal weight to the other two subscales, allowing a total score to be calculated which has the same range (0-12) as the full IS. Higher scores on the IS indicate better insight.

(vii) Economic evaluation:

The number of contacts with therapists was centrally recorded. Other service use was measured for the three months prior to baseline assessment, and 3-, 6- and 9-month follow-up using the Client Service Receipt Inventory $\left(\mathrm{CSRI}^{38}\right)$. The CSRI included health and social care services as well as informal care provided by family/friends specifically because of the patients health problems. Patients were asked how many times specific services had been used, and where relevant they were also asked to state the typical duration of service contacts. Unit costs were attached to the service use measures in order to generate service $\operatorname{costs}^{39}$. Therapy was costed using the unit cost of a psychologist (£77 per hour). Informal care was costed using a unit cost of a homecare worker as a proxy value. This was based on the assumption that in the absence of an informal carer paid help would be required to perform the same tasks

\section{Therapy}

Individuals received six months of therapy. CBTp was based on the Fowler et al manual $^{2}$ (also see Kuipers et $\mathrm{al}^{4}$ ), and was carried out by CBT therapists $(\mathrm{N}=31$; median number of patients seen $=2$; mode $=1$; range 1-7) under the supervision of either EK or EP. Therapists were all trained in CBT, but the majority were not experts in CBTp and received no extra training apart from fortnightly supervision and access to reading materials. They were employed in other jobs (as clinical psychologists, nurses, or psychiatrists), and saw 
PICuP patients during their Continuous Professional Development (CPD) sessions to develop their skills in CBTp.

Sessions were carried out weekly or fortnightly, depending on the preference of the patient, for up to one hour. From the outset there was a specific emphasis on engagement and building a good therapeutic relationship. Flexibility from the therapist was key throughout the therapy to maximise engagement and fit in with the patients' needs. All interventions were formulation driven, and focused on the therapy goals of the patient. For a sizeable proportion of the group, the goals of the patients centred on emotional problems, despite the presence of positive symptoms. This reflects our clinical experience of doing CBTp, which targets distress rather than symptoms per se, whether the distress emanates from symptoms or from concurrent emotional disorders (see also Farhall ${ }^{24}$ ).

Patients received an average of 16 sessions (range 8-28; median $=16$ ), as recommended by the updated NICE guidelines ${ }^{9}$. The number of sessions received by the immediate and delayed therapy groups were similar (median number of sessions in immediate group $=15$, delayed group $=17$, Mann-Whitney $U$ test, $U=307.5, p=.2$ ). A small, random selection of therapy sessions $(n=13)$ were taped and sent to an independent, experienced CBTp therapist to be rated for fidelity of treatment using the Cognitive Therapy Scale for Psychosis $\left(\mathrm{CTS}^{-P} \mathrm{y}^{40}\right)$. The mean rating was 40.7 (range 21-53) out of a maximum of 60 , with $77 \%$ of the tapes scoring above the $50 \%$ mark (ie $>30$ ).

\section{Waiting list control}

Individuals randomised to the waiting list control group received TAU for the first nine months, which usually involved medication and case management in a local NHS community mental health team. After nine months everyone was offered six months of therapy, identical to the immediate therapy group.

\section{$\underline{\text { Participants }}$}


Referrals were deemed suitable for the trial if they were aged between 18-65 years, had at least one distressing and persistent positive symptom of psychosis (score of 3 or above on at least one of the positive symptoms items of the PANSS ${ }^{10}$, accompanied by reported subjective distress), and did not have a primary diagnosis of alcohol or substance abuse or of an organic condition. Only patients who had been stable on medication for a period of at least three months were included (if there had been a recent change in medication, the three months criterion did not apply if the change had been (i) a "downgrade" ie a switch from an atypical to a typical neuroleptic, or (ii) a "sideways" move ie a switch from one atypical to another, or from one typical to another. The three months criterion did apply to a switch from any neuroleptic to Clozapine).

Patients who were suitable but were either unable to complete (e.g., due to language difficulties), or distressed by, the baseline assessments, were also excluded. Thirty per cent of referrals to PICuP $(n=74)$ were recruited into the trial (see Figure 1 for the CONSORT diagram) Thirty-six patients were randomised to the immediate therapy group, and 38 to the waiting list control group.

\section{Insert Figure 1 here - CONSORT diagram}

\section{Power calculation}

The power calculation was carried out on the basis of a difference in reduction of total BPRS ${ }^{11}$ scores between a CBT group and a control group found by Kuipers et $\mathrm{al}^{4}$ (CBT group: mean reduction over trial period $=2.02, \mathrm{SD}=2.31$; control group: mean reduction $=$ $0.46, \mathrm{SD}=2.15)$. This study was chosen to base our power calculations on because of the similarities in the sample (medication resistant group), and the therapy manual followed ${ }^{2}$.A sample size of 34 per group would be needed to detect an effect size of this magnitude or larger with $80 \%$ power and using a two-sided independent samples t-test at the 5\% significance level.

\section{$\underline{\text { Statistical analyses }}$}


The objective of the statistical analyses was to compare outcomes between TAU and CBT arms at the end of therapy and at the three months follow-up. In order to improve the power of our group comparisons, outcome data from the delayed therapy group were also included in our analyses and were combined with the immediate group where possible. Although such a design is less straightforward to analyse, patients being in different groups at different times is not a problem per se. The main issue is whether it is justified to combine the groups. A key assumption that has to be met to allow the groups to be combined is that being on the waiting list (i.e. receiving 'waiting list $+\mathrm{CBT}$ ') was an equivalent treatment to starting $\mathrm{CBT}$ at the beginning of the trial (i.e. receiving 'immediate CBT'). We addressed this issue empirically by testing for outcome differences between 'waiting list $+\mathrm{CBT}$ ' and 'immediate CBT' treatments and only combining the two groups if the relevant test was not statistically significant ie if there was no detectable effect of delaying the therapy. As long as this assumption is met the intervention effects assessed are the same as those obtained in standard RCT designs.

For each outcome, all available data at all time points were used in the formal analyses. This meant that participants in the immediate CBT group contributed up to three measures per outcome (at baseline, six and nine months post baseline) while participants in the delayed therapy group contributed up to five values (at baseline, six, nine, 15 and 18 months post baseline). The end of therapy was defined as six months after baseline for the immediate therapy group and 15 months after baseline for the delayed group. Three months follow up was at nine months after baseline for the immediate therapy group and at 18 months after baseline for the delayed therapy group.

The analysis of our longitudinal design containing between-participant ('waiting list' vs. 'immediate CBT') and within-participant ('waiting list' vs. 'waiting + CBT') factors necessitated the use of linear mixed modelling. Pre-randomisation values were used as a covariate and post-randomisation values as the dependent variable. The analysis was an intention-to-treat analysis, with participants being analysed in the groups to which they were randomised, irrespectively of whether they complied with their allocated treatment. Linear 
mixed modelling is a likelihood approach and therefore valid under the less restrictive assumption that the data are missing at random, unlike LOCF analysis, which has been discredited in the statistical literature for dealing with missing data ${ }^{41}$. The fixed part of the model further contained main effects of group ('waiting list', 'immediate CBT' or 'waiting + CBT'), time point (end of therapy or follow-up) and terms reflecting an interaction between these two factors. The interaction was always included since previous studies have shown that CBT effects can change between the end of therapy and follow-up ${ }^{8}$. Finally, in order to account for correlation between repeated measures the random part of the statistical model included intercepts that varied with participant.

A possible carry-over effect of waiting list on CBT, or in other words an effect of delaying CBT, was assessed by statistically testing the difference between the immediate and the delayed CBT group at the end of therapy and follow-up time points. If no evidence for such an effect could be found (no significant delay by time point interaction or delay main effect) then the immediate and delayed CBT groups were combined into a single, combined CBT group. If there was evidence of such an effect, the two CBT groups were kept separate. A significant effect was found for three of the 12 outcomes analysed (PANSS positive, Hayling Test, and MCQ, uncontrollability of thoughts). Not being able to combine the groups for all outcomes increased the complexity of the interpretations of our findings, since not all outcomes were assessed with the same power. Nevertheless, after careful consideration it was felt that this analytic strategy was preferable to analysing the groups separately for all outcomes, since we would have lost considerable power for $12(80 \%)$ of our outcomes, because of 3 outcomes where the groups could not be combined. It would have also meant doubling the number of analyses carried out.

One of our outcomes $\left(\mathrm{BSI}^{32}\right)$ had a discrete distribution (range from 0 to 28 ) with few above zero values, and was therefore dichotomised ( $0=0$ score, $1=$ score of 1 or above). Clearly a normal distribution could not be assumed and instead this outcome was analysed using a generalised linear mixed model (with Bernoulli distribution and logit link function). 
As a result of this, group effects are measured by odds ratios comparing the odds of suicide ideation between the two groups.

The number of days spent in hospital in the nine months after randomisation was compared between the waiting list and the initial CBT group using a Mann-Whitney U test.

The (generalized) mixed model analyses used all the available data per participant and are based on the less restrictive assumption that missing outcome values occur at random (MAR). In our case this means that explanatory variables included in the models (earlier values of the outcome variable, therapy group and time) were allowed to predict missing values.

The general significance level was set to 5\%. To correct for two time-wise group comparisons per outcome the level for such group tests was set to $2.5 \%$. All analyses were carried out in Stata 9.

\section{Analysis of economic data}

Nine-month costs were compared between the immediate therapy and control group and the delayed therapy and control group, controlling for baseline cost differences. Due to missing data at some time points we imputed costs where necessary using costs from other time points (with the impute function in Stata which uses a best-subset regression method) in order to generate nine-month figures. Cost data are usually skewed due to a small number of patients using high cost services, such as hospital beds. To make valid comparisons between mean costs (which are the most useful measure) we therefore used bootstrapping (which does not rely on any specific distribution) with 10000 repetitions to produce $90 \%$ confidence intervals using the percentile method. $90 \%$ confidence intervals were used because we assumed that people are more prepared to commit a type 1 error (rejecting the null hypothesis of no difference in costs when it is true) with economic data compared to clinical data ${ }^{42}$. Costs were not formally linked to outcomes in the form of a cost-effectiveness analysis. Because the delayed therapy and control group were the same patients we used the cluster option in Stata for this comparison. Given that multiple outcome measures were used it was more appropriate 
to conduct a cost-consequences analysis where costs are viewed alongside outcomes to provide an overall assessment of the intervention.

\section{Results}

Overall our sample was middle-aged (therapy group: mean $=34$ (S.D. $=9.8)$; TAU group: mean $=39.6($ S.D. $=10.2)$, with a preponderance of men (therapy group: 26 males and 10 females; TAU group: 20 males and 18 females), a fairly long history of illness (therapy group: median $=6$ years (range $=0-28$ ), number of days in hospital in the last five years: median $=32($ range $=0-703)$; TAU group: median $=7$ years $($ range $=0-32)$, number of days in hospital in the last five years: median $=50$ (range $=0-1186)$ ), and an average IQ (therapy group: mean $=95.03($ S.D. $=13)$; TAU group: mean $=94.5($ S.D. $=12.6)$ ). They were mostly single (86\% and $76 \%$ in the therapy and TAU groups, respectively), with just over $40 \%$ being non-White ( $47 \%$ and $39.5 \%$ in the therapy and TAU groups respectively). In the therapy group $68 \%$ were on an atypical antipsychotic, $20 \%$ on Clozapine, $6 \%$ were on a typical antipsychotic, and $6 \%$ were unmedicated, with a median percentage of maximum dose $=50($ range $=8-100)$; in the TAU group $49 \%$ were on an atypical antipsychotic, $35 \%$ on Clozapine, $13 \%$ were on a typical antipsychotic, and $3 \%$ were unmedicated, with a median percentage of maximum dose $=50$ (range $=8-125$ (one participant had a daily dose that exceeded the maximum dose by $25 \%)$ ).

As expected from randomisation, the groups were similar in demographics (gender, age, marital status, ethnicity, IQ) and clinical characteristics (total number of days in hospital in the last five years, length of illness, medication dosages).Twenty-five patients in the therapy group (69\%), and 31 in the TAU group (82\%), had auditory hallucinations; 30 patients in the therapy group (83\%), and 30 in the TAU group (79\%), had delusions; 19 patients in the therapy group (53\%), and 23 patients in the TAU group (60\%), had both.

Seventeen patients dropped out of therapy or the trial, 10 from the immediate therapy group, and seven from the TAU group. A further nine people dropped out or could not be 
followed up by the assessors in the delayed therapy group (see Figure 1). Such figures are comparable to other CBTp trials ${ }^{18,43}$, which typically range between $20-30 \%$. Three patients who dropped out from therapy in the immediate therapy group had assessment data available at the end of therapy time point, and one at the follow-up time point. None of the participants who dropped out from therapy in the delayed therapy group had assessment data available at either time point.

There were no significant differences between the patients who remained in the trial and those who dropped out in age $(t=-.04$, d.f. $=72, p=.9)$, IQ $(t=-.39$, d.f. $=66, p=.7)$, gender distribution $\left(\chi^{2}=.01\right.$, d.f. $\left.=1, p=.9\right)$, length of illness (Mann-Whitney $U=4.14 .5, p=$ .3 ), number of days in hospital in the last five years (Mann-Whitney $U=402, p=.2$ ), or medication dosage (Mann-Whitney $\mathrm{U}=367, \mathrm{p}=.9$ ). In addition, some patients were not able to complete all the measures at all assessment time-points, giving variable Ns across measures and time-points.

At six months, five patients in the initial therapy group (20.8\%), and eight patients in the control group (34.8\%), had changed or stopped their medications at some stage in the preceding six months. At nine months a further four $(17.4 \%)$ and five (19.2\%) patients in the therapy and control groups respectively had changed or stopped their medication. In the delayed therapy group, four patients (16\%) changed or stopped their medication during the therapy period, and one further person (3.6\%) changed or stopped medication during the follow-up period. Since the number changing medications in the two groups were remarkably similar, especially in the comparisons between the control group and the combined CBT group, medication change did not qualify to be a confounder (all analyses were in fact redone with medication changes as a covariate, which did not change any of the results).

The outcome raw data and Ns for each outcome are summarised in Table 1 and the results from the statistical analyses are described below. Estimated difference coefficients are reported with $95 \%$ confidence intervals [CIs] in parentheses. Effect sizes $(\eta)$ for continuous outcomes were calculated as the estimated difference divided by the baseline standard 
deviation across both groups. Graphical representations of a selection of significant results are depicted in Figure 2.

The results are reported for the combined therapy group (ie when there was no evidence for an effect of delaying the therapy) unless otherwise specified.

\section{$\underline{\text { Psychotic symptoms }}$}

PANSS positive symptom score:

The comparison of the immediate and the delayed CBT group showed a main effect of delay for this variable $(\mathrm{z}=2.3, \mathrm{p}=0.023)$. Therefore the immediate and delayed therapy groups could not be combined and the two therapy groups were analysed separately. A significant reduction in PANSS positive scores was found for the delayed therapy group compared to the waiting list control group, but not for the immediate therapy group, at both the end of therapy (delayed therapy: $-2.8[-3.9--1.6], \mathrm{p}<.001, \eta=.59$; immediate therapy: $.64[-2.5-1.2], \mathrm{p}=.51, \eta=.13$ ) and the follow-up (delayed therapy: $-1.6[-2.8--.40], \mathrm{p}=$ $.009, \eta=.34$; immediate therapy: $-.53[-1.4-2.4], \mathrm{p}=.58, \eta=.11)$.

\section{PANSS negative symptom score:}

The group difference was not statistically significant at the end of therapy $(-1.3[-3.0-$ .39 ], $\mathrm{p}=.13, \eta=.27)$, but a significant reduction in PANSS negative scores in the combined therapy group compared to the waiting list control group emerged at the follow-up (-2.0 [-3.7 $-. .28], p=.023, \eta=.41)$.

\section{Emotional problems:}

PANSS general symptom score:

There was a significant reduction in PANSS general scores in the combined therapy group compared with the waiting list control group at the end of therapy $(-3.1[-5.8--.53], \mathrm{p}=$ $.019, \eta=.45)$, but not at the follow-up $(-1.2[-3.9-1.4], \mathrm{p}=.37, \eta=.17)$.

\section{Beck scales}


The BSI was transformed into a categorical variable, with those scoring 0 being assigned to the non-suicidal group, and those scoring above 0 being assigned to the suicidal group.

At the end of therapy there was a significant reduction in both depression (-2.8 [-5.2 $-.46], \mathrm{p}=.02, \eta=.24)$ and anxiety $(-3.2[-5.7--.80], \mathrm{p}=.009, \eta=.28)$ in the combined therapy group compared to the control group, and reduced odds of being suicidal in the combined therapy group compared to the waiting list control group (OR=.09 [.02 -.53], $\mathrm{p}=.008)$. Depression was the only variable to remain significantly reduced in the combined therapy group compared to the control group at the follow-up (depression: $-3.0[-5.4--.65], \mathrm{p}=.01$, $\eta=.26$; anxiety: $-1.7[-4.2-.77], \mathrm{p}=.18, \eta=.15$; suicidal ideation: $\mathrm{OR}=.32[.07-1.6], \mathrm{p}=$ $.16)$.

\section{Self-esteem}

The group differences were not statistically significant at either time point (end of therapy: $-1.2[-2.6-.18], \mathrm{p}=.09, \eta=.20$; follow-up: $-1.2[-2.6-.21], \mathrm{p}=.09, \eta=.20)$.

\section{$\underline{\text { Social and cognitive functioning }}$}

\section{Brixton and Hayling tests:}

There was a main effect of delay for the Hayling test $(\mathrm{z}=2.2, \mathrm{p}=0.027)$, and the two therapy groups were analysed separately for this measure. No significant differences were found on the Brixton test at either time-point (end of therapy: .50 [-.18 - 1.2], $\mathrm{p}=.15, \eta=.23$; follow-up: .43 [-.22 - 1.1], $\mathrm{p}=.20, \eta=.19)$. In contrast, at both time-points there were significant improvements on the Hayling test for the delayed therapy group compared to the waiting list control group (end of therapy: .92 [.30 - 1.5], $\mathrm{p}=.004, \eta=.60$; follow-up: 1.0 [.41 - 1.6], $\mathrm{p}=.001, \eta=.65$ ), but not for the immediate therapy group (end of therapy: .08 [-.74 $.91], \mathrm{p}=.84, \eta=.05 ;$ follow-up: $.17[-.61-.95], \mathrm{p}=.67, \eta=.11)$. 
There was a significant improvement in SOFAS scores in the combined therapy group compared to the waiting list control group at the end of therapy $(6.0$ [2.1 - 9.9], $\mathrm{p}=$ $.002, \eta=.49)$, but not at follow-up (2.9 [-1.0 - 6.9], $\mathrm{p}=.14, \eta=.24)$.

\section{Number of days spent in hospital}

The number of days spent in hospital was only available for the nine months following randomisation, and not the nine months following therapy (ie there were no data available for the nine months following the delayed therapy group). There were no significant differences between the immediate and waiting list control groups on this variable (MannWhitney $\mathrm{U}=611.5 ; \mathrm{p}=.19)$.

\section{$\underline{\text { Insight }}$}

No statistically significant effects were found at either time-point (end of therapy: $.03[-.83-.78], \mathrm{p}=.95, \eta=.01 ;$ follow-up: $.10[-.71-.92], \mathrm{p}=.81, \eta=.03)$.

\section{$\underline{\text { Beliefs about symptoms }}$}

\section{Beliefs about Voices Questionnaire-Revised}

Malevolence: No statistically significant effects were found for this variable at either time-point (end of therapy: $-1.4[-2.9-.08], \mathrm{p}=.063, \eta=.23$; follow-up: $-.44[-2.0-1.1], \mathrm{p}=$ $.57, \eta=.07)$.

Omnipotence: No statistically significant effect was found for this variable at the end of therapy $(-.91[-2.5-.65], \mathrm{p}=.25, \eta=.20)$, although a significant reduction in omnipotence scores in the combined therapy groups compared to the waiting list control group emerged at the follow-up $(-2.4[-4.0--.86], \mathrm{p}=.002, \eta=.53)$.

Resistance: There was a significant reduction in resistance scores in the combined therapy group compared to the waiting list control group at the end of therapy (-3.5 [-5.7 - $1.3], \mathrm{p}=.002, \eta=.56)$, but not at the follow-up (.33 [.07 - 1.5], $\mathrm{p}=.16, \eta=.05)$. 
Meta-cognitions Questionnaire (Negative beliefs about the controllability of thoughts)

The immediate and delayed therapy groups could not be combined for this variable due to a main effect of delayed therapy $(\mathrm{z}=3.1, \mathrm{p}=0.002)$, and the two therapy groups were therefore analysed separately. At both time points there were significant reductions in scores in the immediate therapy group compared to the waiting list control group (end of therapy: $12.0[-18.0--6.2], \mathrm{p}<.001, \eta=.94$; follow-up: $-7.0[-12.8--1.2], \mathrm{p}=.018, \eta=.55)$, but not for the delayed therapy group (end of therapy: $-3.6[-7.7-.45], \mathrm{p}=.081, \eta=.28$; follow-up: 1.5 [$2.5-5.5], \mathrm{p}=.47, \eta=.12)$.

\section{$\underline{\text { Economic evaluation }}$}

\section{The Client Service Receipt Inventory:}

Service use and costs (excluding the CBT itself) are shown in Table 2. The contacts relate just to those patients using specific services whilst the costs are for the whole group at each time point. Inpatient costs and informal care costs accounted for most of the total at each time point and in each group. The mean (SD) cost of CBT for those in the immediate therapy group was $£ 939$ ( $£ 508$ ). Adding this to the cost of other services used in the nine months following the start of treatment results in a mean total cost for the immediate therapy group of $£ 11775$ (£11058), which is higher than the nine-month costs for the control group - £9651 (£12162). However, this difference was not statistically significant (90\% CI, $-£ 2383$ to $£ 3345)$.

The CBT costs for the delayed therapy group were $£ 1013$ (£639), resulting in a total for the nine months after the start of therapy of $£ 8618$ (£6092). Comparing this to the control condition costs revealed a non-significant cost difference (90\% CI, - $£ 1882$ to $£ 621)$.

\section{Discussion}

The aim of this trial was to evaluate the impact of CBTp delivered by non-expert, but supervised, clinicians on a wide range of outcomes. The results were not clear-cut, with some 
variables improving in the immediate, but not the delayed, therapy group, while others were significant at one time point but not the other, rendering it difficult to make firm conclusions about which areas of functioning are ameliorated by CBTp. It is likely that these findings are a reflection of the fact that therapy goals vary widely between patients, and that the groups could not be combined for all outcomes, which, in addition to missing data, led to unevenness of power across different outcomes at different time points.

Overall, the only robust improvement was in depression, where significant effects were shown in the combined therapy group at both the end of therapy and follow-up, replicating the recent Garety et al trial ${ }^{18}$. The cost analysis showed no differences between therapy and TAU groups. There were also further encouraging but modest improvements found in both emotional and cognitive variables, in addition to psychotic symptoms, although overall only $40 \%$ of our comparisons showed a significant difference.

Enduring improvement were shown for positive symptoms of psychosis, as you would expect from a therapy that targets predominantly distress associated with positive psychotic symptoms. However, significant effects at both time points were found in the delayed therapy group only, suggesting improvements may not be consistent across individuals.

Other areas targeted by CBTp, but seldom assessed in trials so far, namely the process of thinking rather than merely the content of thought, also showed enduring improvements. Thus, cognitive flexibility, as measured by the Hayling ${ }^{35}$, and negative beliefs about the danger associated with the uncontrollability of thoughts, as measured by the Meta-Cognitions Questionnaire $^{28}$, were improved at both the end of therapy and the follow-up stage, and showed larger effect sizes (ranging from .55 to .94 ) than positive symptoms and depression (ranging from .24 to .59). This is potentially an important finding since so much of CBT consists of changing current patterns of thinking and how people relate to their thoughts and symptoms (e.g., 'decentring ${ }^{44,45}$ ), rather than merely discussing the evidence for and against the veracity of their thoughts. This is especially the case in CBTp, where challenging delusions and the reality of people's experiences are contra-indicated, and much work is done 
on process rather than content. Nevertheless, again the above effects reached significance in only one of the two therapy groups, and therefore may not be consistent across individuals.

There were a number of other significant findings at the end of therapy, which were consistent in both therapy groups, but which were not maintained three months later. Anxiety and suicidal thinking were both improved after six months of therapy, as were general symptoms of the PANSS ${ }^{10}$, and social and occupational functioning. Again, these gains would be expected with CBTp, which aims not just to decrease positive symptoms of psychosis but to reduce distress and disability ${ }^{2}$. Although these gains were no longer significant at the follow-up stage, it can be seen from Figure 2 that it appeared to be the control group which improved in the last three months, rather than the therapy group deteriorating to pre-therapy levels; the latter appeared to stay constant during the follow-up period (indeed this pattern was true for most variables, including those where significant differences remained). One possibility is that this pattern is merely a reflection of the cyclical nature of psychosis. Other studies have found it difficult to demonstrate significant enduring improvements in the therapy group against a backdrop of natural remission in the control group ${ }^{8,18}$. However, this explanation is less likely to be valid in a medication-resistant sample, who show residual and enduring distressing symptoms of psychosis. Furthermore, for many of the outcomes the improvements in the control group were seen in the last three months before starting therapy, following a fairly stable six months period. Another possibility is that the control group improved as a result of knowing they were about to receive therapy shortly, potentially suggesting that being on a time limited waiting list for therapy is a therapeutic tool in itself, akin to a placebo effect ${ }^{46}$. In addition, the input of the research assistants, who met with them to complete the assessments every three months, may also have been therapeutic. Indeed, Sensky et $\mathrm{al}^{8}$ found that befriending improved outcome, although the improvements were short-lived.

Interestingly, emotional and behavioural response to voices was also altered at the end of therapy, such that resistance to voices was diminished. At the follow-up stage, beliefs about the omnipotence of voices became significantly reduced. These results suggest that 
omnipotence beliefs and response to voices are important areas that can possibly be changed in CBTp, over and above the frequency of voices. Again this is potentially an important finding, since beliefs about voices are more predictive of distress than severity and frequency of voices ${ }^{47,48,49}$. A change in beliefs about voices also echoes the actual process of CBTp, since most of the therapeutic work concentrates on people's appraisals, and relationship with, their voices, with the aim of rendering them less distressing, rather than on changing the actual physical occurrence of hallucinations $\mathrm{s}^{3,19}$.

One unexpected finding was the reduction of negative symptoms at the follow-up stage, since CBTp tends to concentrate on the distress associated with positive, rather than negative, symptoms of psychosis. However, CBTp does address depression and functioning, with which there is a certain degree of overlap. Indeed, it has been argued that negative symptoms are manifestations of underlying defeatist and negativistic cognitions ${ }^{50}$. It may be that while improvements in overall depressive symptoms appear immediately after therapy ends, knock-on effects on negative symptoms take more time to manifest, as has previously been found with other symptoms of psychosis ${ }^{8}$.

It is noteworthy that insight was not changed by CBTp in this trial. It is unlikely that this lack of change was due to a ceiling effect, since insight in the traditional sense ie recognising that one has a mental illness, is not a prerequisite of CBTp, and was not a criterion for referral or selection into the trial. Indeed the mean scores on the Insight Scale $\left(\mathrm{IS}^{37}\right)$ of the current sample were similar to the published norms for this population. Although some variants of CBTp have targeted insight specifically ${ }^{23}$, the CBTp model followed in the current study ${ }^{2}$ does not stipulate that patients should be encouraged to reconceptualise their psychotic experiences within a medical model. Rather, therapists work within the broad model of understanding that their patients present with ${ }^{51,52,,}$, attempting to modify it and enrich it with a more psychological framework, so that distress can be reduced. Gaining insight, in the sense of accepting a label of mental illness, is not always helpful to individuals in terms of reducing their distress ${ }^{53,54}$. Furthermore, Brett $^{55}$ found that medical model appraisals of anomalous experiences were related to increased distress in a group of 
undiagnosed and diagnosed individuals, while normalising and spiritual appraisals of the same experiences were related to less distress. Therefore an improvement in traditional 'insight' with CBTp is perhaps neither to be expected nor desirable. It is possible that the use of a more sophisticated measure of psychological, rather than purely medical, insight, such as the more recently published Beck Cognitive Insight Scale ${ }^{56}$, would have captured changes with CBTp, as found by Granholm et $\mathrm{al}^{57}$.

\section{$\underline{\text { Limitations }}$}

A number of methodological problems that are common in trials of psychological therapies also apply to this trial. The inclusion and exclusion criteria meant that only individuals who spoke good English, and were able to complete the assessments, were recruited. Furthermore, we depended on referrals to a psychological therapies clinic, who were motivated to attend and engage in therapy, rather than sampling from a representative sample of outpatients with psychosis. However, all psychological therapies clinics in routine NHS services operate this level of triage, regardless of type of disorder, since psychological treatment is a question of choice on the participant's part. As such, our sample was likely to be representative of people with psychosis seen in psychological therapies clinics.

We were unable to look at potential therapist effects due to the small sample size and the large number of therapists, with the modal number of patients seen by therapists being one. Previous studies have found that therapist expertise contributes to the variance in outcome $^{58}$, and therefore may have been a factor in this study.

There were a large number of analyses conducted on a relatively small sample, thus increasing the likelihood of Type 1 errors. The lower significance level of .025 was adopted to adjust for the two post hoc group comparisons carried out at the end of therapy and the follow-up stages, but a large number of variables were still tested at both time points. Adjusting for multiple outcomes was not appropriate in this case, since we had a-priori reasons for including a range of different variables, and the study was not powered for Bonferroni corrections, and would therefore have led to Type II errors. The specific aim of 
this trial was to assess a wide range of outcomes, since it reflects the actual process of individualised, formulation-based CBTp. Therapists address what is on the patient's 'problem list', which will differ extensively between individuals. Indeed, for some patients the emotional problems they face are more difficult to bear than their symptoms of psychosis, and Farhall et $\mathrm{al}^{24}$ also noted that a majority of their sessions had emotional problems as their foci. Therefore we would argue that measuring positive symptoms only as the main outcome of CBTp will not necessarily capture meaningful change for individuals, despite the fact that a narrow set of outcomes is the preferable statistical option. Future trials will need to circumvent this problem by the use of new measures which encompass a range of problem areas, such as CHOICE (CHoice of Outcome In Cbt for the psychosEs ${ }^{59}$ ), which was designed in consultation with service-users specifically to address more closely the aims of CBT and the outcomes of import to service-users.

There were a number of further statistical limitations. As well as Type 1 errors, the small sample combined with missing data meant that power was low on some of the analyses, and may have led to Type II errors. This was especially the case for measures relating to hallucinations (such as the BAVQ-R), and where the therapy groups could not be combined. Second, the fairly high level of drop-outs means that there may have been a degree of selection in those who completed therapy and the assessments, despite the fact that they did not differ on any demographic variables. Although we carried out an intention-to-treat analysis, only a few of the people who dropped out from therapy consented to be assessed at the six and nine months time points, and most could not therefore be included in the analyses. It was not possible to determine patients' reasons for dropping-out, since ethical requirements meant that the protocol of the study specified that they could withdraw at any time without justifying their decision.

A third statistical limitation was the amalgamation of the immediate and delayed therapy groups, although this procedure is increasingly being used in RCTs of psychological therapy ${ }^{25,26}$. This design was adopted from the outset, partly to increase power. However this meant that we had to assume that immediate and delayed CBT were equivalent. Extra model 
assumptions were then required to deal with the increased number of repeated measures for participants originally allocated to the waiting list. We assessed effects of delaying CBT empirically and found no evidence of such effects for most outcomes, but such assessment might also have suffered from lack of power. Furthermore, for some of the analyses where the groups could not be combined, the significant effects were found only in one of the two therapy groups. This may be especially problematic when the significant effects were found only in the within-participants comparisons (i.e., the delayed therapy group). This was the case for positive symptoms and cognitive flexibility. These latter findings therefore need to be interpreted with more caution than our other outcomes, as the significant improvements may have resulted from the combined effects of being on the waiting list and therapy, rather than therapy alone.

There were a number of other methodological limitations, such as the lack of blindness of the independent assessors. Tarrier $\&$ Wykes $^{60}$ demonstrated an inverse relationship in published CBTp trials between the design rigour, especially blindness, and the effect size found, although not all meta-analyses have found this ${ }^{61}$. The context of the current study, namely running a trial within a routine clinic setting, meant that the ecological validity of the findings was increased at the expense of some methodological rigour. Nevertheless, the lack of blindness limitation applies to the interview-based measures only (ie PANSS and SOFAS), since the remaining 10 measures were self-rated, and the majority of our findings are therefore not subject to this bias. Nevertheless, the patients themselves were not blind to group allocation, and the self-report data may therefore also reflect expectancies of change rather than equate with objectively measured change.

The follow-up period was short i.e., three months, compared to some trials which have followed people up for two years or more. However the design of this study, where people were offered therapy after having been in the waiting list control group, prevented us from being able to carry out a more extensive follow-up. We also had no control over medication changes or stoppages. However, the medication changes were equally distributed across the groups, and were therefore not considered to be a confounding variable. All 
analyses were in fact repeated including this variable as a covariate in the models, and did not impact on the findings. Lastly, no control therapy was included in this trial due to limited resources, which means that some of the observed effects may have occurred via non-specific factors in the therapeutic contact.

\section{Clinical implications}

Bearing in mind the limitations delineated above, this trial still has some tentative but encouraging clinical implications. First, the results suggest that CBTp may incur modest improvements on individuals' functioning in a number of different domains, which include emotional problems, beliefs about and response to voices, and thinking processes, in addition to positive and negative symptoms. They map onto what clinicians would identify as the primary targets in CBTp, which recognise that people with psychosis should be viewed as individuals with an intertwined set of difficulties rather than "walking illnesses". The lack of a consistent picture of change across the two therapy groups for those outcomes where the groups were analysed separately may be a reflection of the individualised nature of CBTp, whereby improvements can only be expected to occur in those areas that are targeted in the sessions, which is likely to differ across individuals.

Second, the findings suggest that CBTp can be effective with non-expert therapists delivering therapy in a routine, NHS outpatient service, at least in reducing depression. Efficacy trials, although influential in the current British NICE guidelines ${ }^{9}$, can nevertheless run the risk of being seen as irrelevant by clinicians, because of the perceived gulf between research settings and the constraints experienced during routine clinical work. It is hoped that the current trial goes towards bridging this gap. However, it should be noted that although no specific training was given for the purposes of the trial, our therapists were all previously trained in general CBT, and received ongoing fortnightly group supervision throughout therapy. Furthermore, they had protected time as part of their CPD for their cases and for supervision. There is increasing evidence that attempts to deliver complex therapies such as 
CBTp by care-coordinators or staff with limited training only, or by adequately trained therapists but without protected time or supervision, are not likely to be productive ${ }^{62}$.

Third, our results provide some support for the previous and updated NICE guidelines ${ }^{9}$, which stipulate that CBTp works best for the 'medication-resistant' group. All of our patients had ongoing distressing symptoms of psychosis, but were stable enough to be seen as outpatients. The median number of therapy sessions was 16 , delivered over a period of six months, in line with the updated recommendations. Our results also add to the evidence base that the best use of limited CBT resources is to target help-seekers, rather than an unselected population $^{18,24}$.

Fourth, some of the improvements observed at the end of therapy were no longer significant three-months later. Potentially these results suggest that therapy should be augmented by booster sessions to ensure long-lasting results. However, as noted, for most variables the lack of significance at the follow-up appeared to be related to the control group improving in the last few months prior to starting therapy, rather than the therapy group losing their gains.

Finally, the results of the cost analysis found no significant differences between groups, consistent with the updated NICE guidelines that also found that CBTp did not cost more. There was some suggestion that the costs of therapy may be offset by reduced costs of hospitalisation, but given the large standard deviations we need to be cautious about this finding. Carrying out cost analyses in trials is an important endeavour in the current climate of service providers in the UK and elsewhere, where the cost benefits of healthcare are under close scrutiny. Unfortunately, too often psychological therapies are seen as interventions which can only thrive in resource-rich times. However the present findings, in combination with previous studies ${ }^{9}$, suggest that such therapy need not add to overall costs in the NHS.

To conclude, the results showed that the only robust and enduring improvements in a trial of CBTp carried out by non-expert therapists were in depression. Nevertheless, there was some support for further modest improvements in a number of other domains addressed by 
CBTp. Both emotional (depression, anxiety, suicidal ideation), and cognitive (beliefs about voices, uncontrollability of thoughts, cognitive flexibility) variables, may be improved, in addition to psychotic symptoms, although these improvements may not be consistent across individuals and may not last once therapy has finished. There was no overall difference in costs between the groups, although this lack of difference may have been due to large variability across participants. .

\section{$\underline{\text { Acknowledgements }}$}

We would like to thank all the service -users, clinical teams in the South London and Maudsley Foundation NHS Trust and other South East sector NHS Trusts, and therapists who participated in the trial.

A preliminary version of this paper was presented at the 11th International Congress On Schizophrenia, Colorado Springs, USA (Peters, E. et al (2007) A Randomised Controlled Trial (RCT) of Cognitive Behaviour Therapy (CBT) for psychosis in a routine clinical service: Looking beyond the PANSS ... Schizophrenia Bulletin, 33, 601).

\section{Funding}

The study was supported initially by Culyer funding from the Department of Health, U.K., and subsequently by a donation from Eli Lilly.

\section{References}

1. Wykes, T., Steel, C., Everitt, B. \& Tarrier, N. (2008) Cognitive Behavior Therapy for schizophrenia: Effect sizes, clinical models, and methodological rigor. Schizophrenia Bulletin, 34, 523-537.

2. Fowler, D., Garety, P.A. \& Kuipers, E. (1995) Cognitive Behaviour Therapy for Psychosis: Theory and Practice. Chichester: Wiley.

3. Chadwick, P., Birchwood, M. \& Trower, P. (1996) Cognitive Therapy for Delusions, Voices and Paranoia. Chichester: Wiley

4. Kuipers, E., Garety, P., Fowler, D., Dunn, G., Bebbington, P., Freeman, D. \& Hadley, C. (1997) London-East Anglia randomised controlled trial of cognitivebehavioural therapy for psychosis. I: Effects of the treatment phase. British Journal of Psychiatry 171, 319-327. 
5. Tarrier, N., Yusupoff, L., Kinney, C., McCarthy, E., Gledhill, A., Haddock, G. \& Morris, J. (1998) Randomised controlled trial of intensive cognitive behaviour therapy for patients with chronic schizophrenia. British Medical Journal, 317, 303-307.

6. Garety, P. A., Fowler, D., Kuipers, E., Freeman, D., Dunn, G., Bebbington, P., Hadley, C. \& Jones, S. (1997). "London-East Anglia randomised controlled trial of cognitive-behavioural therapy for psychosis. II: Predictors of outcome.” British Journal of Psychiatry, 171: 420-426.

7. Miles, H., Peters, E.R., \& Kuipers, E. (2007) Service-user satisfaction with CBT for psychosis. Behavioural \& Cognitive Psychotherapy, 35, 109-117.

8. Sensky, T., Turkington, D., Kingdon, D., Scott, J.L., Scott, J., Siddle, R., O'Carroll, M. \& Thomas, R.E.B. (2000) A randomised controlled trial of cognitive-behavioral therapy for persistent symptoms in schizophrenia resistant to medication. Archives of General Psychiatry, 57, 165-172.

9. NICE (2003) Schizophrenia; Full National Clinical Guideline on Core Interventions in Primary and Secondary Care. London, Gaskell Press. Updated guideline, (2009)

10. Kay, S.R., Opler, L.A. \& Lindenmayer, J.P. (1987) The Positive and Negative Syndrome Scale (PANSS) for Schizophrenia. Schizophrenia Bulletin, 13, 261-276.

11. Overall, J.E., \& Gorham, D.R. (1962) The Brief Psychiatric Rating Scale. Psychological Reports, 10, 799-812.

12. Asberg, M., Montgomery, S., Perris, C., Schalling, D., Sedvall, G. (1978). The comprehensive psychopathological rating scale. Acta Psychiatrica Scandinavica, Suppl 271, 5-27.

13. Leucht, S., Davis, J.M., Engel, R.R., Kissling, W. \& Kane, J.M. (2008). Definitions of response and remission in schizophrenia: recommendations for their use and their presentation. Acta Psychiatrica Scandinavica, 119, 7-14.

14. Kapur, S. (2004). How anti psychotics become anti-'psychotic' - from dopamine to salience to psychosis. TrendsPharmacological Science, 25(8), 402-406.

15. Kumari V. (2006). Do psychotherapies produce neurobiological effects? Acta Psychiatrica Scandinavica, 18, 61-70.

16. Birchwood, M. \& Trower, P. (2006) The future of CBT for psychosis: not a quasineuroleptic. British Journal of Psychiatry, 188, 107-108.

17. Steel, C., Garety, P.A., Freeman' D., Craig, E., Kuipers' E., Bebbington, P., Fowler, D. \& Dunn, G. (2007) The multi-dimensional measurement of the positive symptoms of psychosis. The International Journal of Methods in Psychiatric Research, 16, 88-96.

18. Garety, P.A., Fowler, D.G., Freeman, D., Bebbington, P., Dunn G. \& Kuipers, E. (2008) Cognitive-behavioural therapy and family intervention for relapse prevention and symptom reduction in psychosis: randomised controlled trial. British Journal of Psychiatry, 192, 412-423. 
19. Trower, P., Birchwood, M., Meaden, A., Byrne, S., Nelson, A. \& Ross, K. (2004) Cognitive therapy for command hallucinations: randomised controlled trial. British Journal of Psychiatry, 184, 312-320.

20. Fowler, D., Hodgekins, J., Painter, M., Reilly, T., Crane, C., Macmillan, I., Mugford, M., Croudace, T. \& Jones, P.B. (2009) Cognitive behaviour therapy for improving social recovery in psychosis: a report from the ISREP MRC Trial Platform study (Improving Social Recovery in Early Psychosis). Psychological Medicine, 39, 16271636.

21. Rusch, N., Corrigan, P.W., Wassell, A., Michaels, P., Olschewski, M., Wilkniss, S., \& Batia, K. (2009). Ingroup perception and responses to stigma among persons with mental illness. Acta Psychiatrica Scandinavica, 120, 320-328.

22. May, R. (2000) Routes to recovery from psychosis: the roots of a clinical psychologist. Clinical Psychology Forum, 146, 6-10.

23. Turkington, D., Kingdon, D., \& Turner, T. (2002) Effectiveness of a brief CBT intervention in the treatment of schizophrenia. British Journal of Psychiatry, 180, 523527.

24. Farhall, J., Freeman, N.C., Shawyer, F., \& Trauer, T. (2009) An effectiveness trial of CBT in a representative sample of outpatients with psychosis. British Journal of Clinical Psychology, 48, 47-62.

25. Dugas, M.J., Ladouceur R., Leger, E., Freeston, M.H., Langlois, F., Provencher, M.D., \& Boisvert, J. (2003) Group CBT for generalized anxiety disorder: Treatment outcome and long-term follow-up. Journal of Consulting and Clinical psychology, 71, $821-825$

26. Duffy, M., Gillespie, K., \& Clark, D.M. (2007) Post-traumatic stress disorder in the context of terrorism and other civil conflict in Northern Ireland: randomised controlled trial. British Medical Journal, 334, 1147-1150.

27. Chadwick, P., Lees, S., \& Birchwood, M. (2000). The revised Beliefs About Voices Questionnaire (BAVQ-R). British Journal of Psychiatry, 177, 229-232.

28. Cartwright-Hatton, S. \& Wells, A. (1997). Belief about worry and intrusions: The Meta-Cognitions Questionnaire and its correlates. Journal of Anxiety Disorders, 11(3), 279-296.

29. Morrison, A.P. \& Wells, A. (2003) Metacognition across disorders: comparisons of patients with hallucinations, delusions, and panic disorder with non-patients. Behaviour Research and Therapy, 41, 251-256.

30. Beck, A.T., Steer, R.A. \& Brown, G.K. (1996) Manual for the Beck Depression Inventory, 2nd Edition. The Psychological Corporation, San Antonia, TX.

31. Beck, A. T., Epstein, N., Brown, G., \& Steer, R. A. (1988). An inventory for measuring clinical anxiety: Psychometric properties. Journal of Consulting and Clinical Psychology, $56,893-897$.

32. Beck, A. T., Kovacs, M., \& Weisman, A. (1979). Assessment of suicide intention: the scale for suicide ideation. Journal of Consulting and Clinical Psychology, 47, 343-352. 
33. Rosenberg, M. (1965). Society and the Adolescent Self-Image. Princeton, N.J.: Princeton University Press.

34. Goldman, H.H., Skodol, A.E., \& Lave, T.R. (1992) Revising Axis V for DSM-IV: A review of measures of social functioning. American Journal of Psychiatry, 149, 11481156.

35. Burgess, P. \& Shallice, T. (1996) Response suppression, initiation and strategy use following frontal lobe lesions. Neuropsychologia, 34, 263-273.

36. Ammons, R.B. \& Ammons, C.H. (1962) Quick Test. Missoula, MT: Psychological Test Specialists.

37. Birchwood, M., Smith, J., Drury, V., Healy, J., Macmillan, F., \& Slade, M. (1994) A self-report Insight Scale for psychosis: Reliability, validity and sensitivity to change. Acta Psychiatrica Scandinavica, 89, 62-67.

38. Beecham, J. \& Knapp, M.R.J. (1992) Costing psychiatric interventions. In G. Thornicroft, C. Brewin \& J. Wing (Eds.) Measuring Mental Health Needs. Pp. 163-183. London: Gaskell.

39. Curtis L, \& Netten A (2005) Unit costs of health and social care. Canterbury, Personal Social Services Research Unit.

40. Haddock, G., Devane, S., Bradshaw, T., McGovern, J., Tarrier, N., Kinderman, P., Baguley, I., Lancashire, S. \& Harris, N. (2001) An investigation into the psychometric properties of the cognitive therapy scale for psychosis (CTS-Psy). Behavioural \& Cognitive Psychotherapy, 29, 221-233.

41. Lane, P. (2008). Handling drop-out in longitudinal clinical trials: a comparison of the LOCF and MMRM approaches. Pharmaceutical Statistics, 7, 93-106.

42. McCrone, P., Knapp M., Proudfoot J., Ryden C., Cavanagh K., Shapiro D., Ilson S., Gray J., Goldberg D., Mann A., Marks I., Everitt B., \& Tylee A. (2004) Costeffectiveness of computerised cognitive behavioural therapy for anxiety and depression in primary care. British Journal of Psychiatry, 185, 55-62.

43. Valmaggia, L.R., van der Gaag, M., Tarrier, N., Pijnenborg, M. \& Slooff, C.J. (2005) Cognitive-behavioural therapy for refractory psychotic symptoms of schizophrenia resistant to atypical antipsychotic medication. British Journal of Psychiatry, 186, 324-330.

44. Moore, R.G. (1996) It's the thought that counts: The role of intentions and metaawareness in cognitive therapy. Journal of Cognitive Psychotherapy: An International Quarterly, 10, 255-269.

45. Teasdale, J.D., Moore, R.G., Hayhurst, H., Pope, M., Williams, S., \& Segal, Z.V. (2002) Metacognitive awareness and prevention of relapse in depression: empirical evidence. Journal of Consulting and Clinical Psychology, 70, 275-287.

46. Kirsch, I. (2005) Placebo psychotherapy: Synonym or oxymoron? Journal of Clinical Psychology, 61, 791-803.

47. Chadwick, P., \& Birchwood, M. (1994) The omnipotence of voices: A cognitive approach to auditory hallucinations. British Journal of Psychiatry, 164, 190-201. 
48. Van der Gaag, M., Hageman, M. C., \& Birchwood, M. (2003). Evidence for a cognitive model of auditory hallucinations. The Journal of Nervous and Mental Disease, 191, 542-545.

49. Peters, E.R., Williams, S.L., Cooke, M.A., \& Kuipers, E. It's not what you hear, it's the way you think about it. Submitted for publication.

50. Rector, N.A, Beck, A. T \& Stolar, N. (2005) The negative symptoms of schizophrenia: A cognitive perspective. Canadian Journal of Psychiatry, 50, 247-257.

51. Peters, E.R. (2007) Assessment in psychosis. Journal of the Norwegian Psychological Association, 5, 527-536.

52. Johns, L., Peters, E.R. \& Kuipers, E. (2007) Psychosis: Intervention. In S.J.E. Lindsay \& G.E. Powell (Eds) The Handbook of Clinical Adult Psychology. ${ }^{\text {rd }}$ Edition. Routledge.

53. Mintz, A. R., Dobson, K. S., \& Romney, D. M. (2003) Insight in schizophrenia: a metaanalysis. Schizophrenia Research, 61, 75-88.

54. Cooke, M.A., Peters, E.R., Greenwood, K. E., Fisher, P.L., Kumari, V. \& Kuipers, E. (2007) Insight in Psychosis: the Influence of Cognitive Ability and Self-Esteem. British Journal of Psychiatry, 191, 234-237

55. Brett, C. (2004) Anomalous Experiences and Cognitive Processes in the Development of Psychosis. Unpublished Ph.D. Thesis: University of London.

56. Beck, A.T., Baruch, E., Balter, J.M., Steer, R.A. \& Warman, D.M. (2004) A new instrument for measuring insight: the Beck Cognitive Insight Scale. Schizophrenia Research, 68, 319-329.

57. Granholm, E.; McQuaid, J.R; McClure, F.S.; Auslander, L.A; Perivoliotis, D.; Pedrelli, P.; Patterson, T.; Jeste, D.V. (2005) A Randomized, Controlled Trial of Cognitive Behavioral Social Skills Training for Middle-Aged and Older Outpatients With Chronic Schizophrenia. American Journal of Psychiatry. Vol 162(3), 520-529.

58. Wykes, T., Hayward, P., Thomas, N., Green, N., Surguladze, S., Fannon, D., Landau, S. (2005) What are the effects of group cognitive behaviour therapy for voices? A randomised controlled trial. Schizophrenia Research, 77, 201-210.

59. Greenwood, K.E., Sweeney, A., Williams, S., Garety, P.A., Kuipers, E., Scott J. \& Peters, E.R. (In Press) CHoice of Outcome In Cbt for psychosEs (CHOICE): The development of a new service-user led outcome measure of CBT for Psychosis. Schizophrenia Bulletin.

60. Tarrier, N. \&Wykes, T. (2004) Is there evidence that cognitive behaviour therapy is an effective treatment for schizophrenia? A cautious or cautionary tale? Behaviour Research \& Therapy, 42, 1377-1401.

61. Zimmermann, G., Favrod, J., Trieu, V.H. \& Pomini, V. (2005) The effect of cognitive behavioural treatment on the positive symptoms of schizophrenia spectrum disorders: A meta-analysis. Schizophrenia Research, 77, 1-9. 
62. Brooker, C \& Brabban, A. (2004). Measured Success: A Scoping Review of Evaluated Psychosocial Intervention Training for Work with People with Serious Mental Health Problems. NIMHE/Trent WDC. 
Table1: Means, standard deviations, and Ns for the outcome variables in the immediate therapy, waiting list control, and delayed therapy groups.

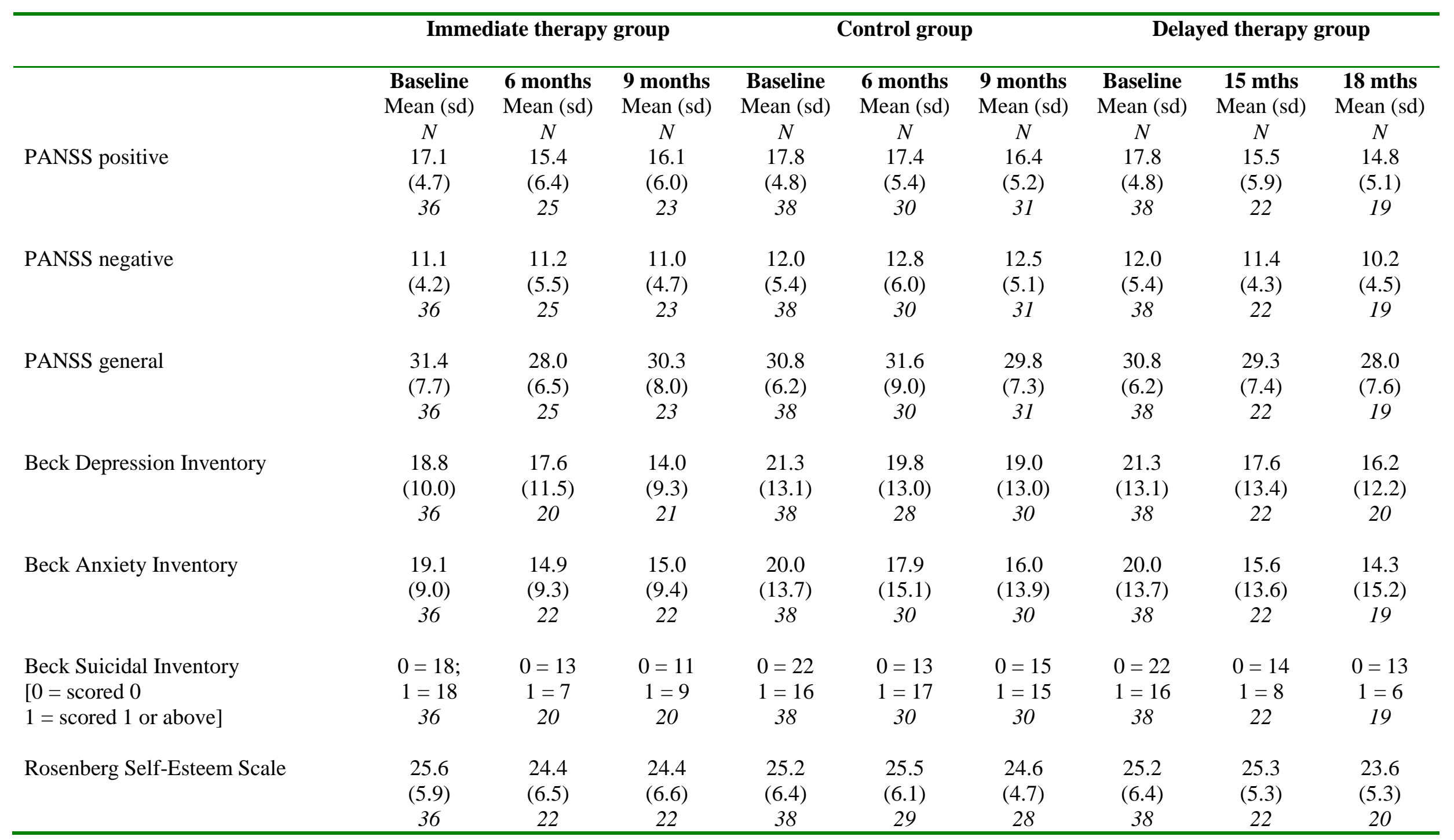




\begin{tabular}{|c|c|c|c|c|c|c|c|c|c|}
\hline Brixton test & $\begin{array}{c}5.3 \\
(2.2) \\
36\end{array}$ & $\begin{array}{c}6.2 \\
(2.4) \\
12\end{array}$ & $\begin{array}{c}6.8 \\
(2.4) \\
16\end{array}$ & $\begin{array}{c}4.6 \\
(2.2) \\
38\end{array}$ & $\begin{array}{c}4.6 \\
(2.8) \\
22\end{array}$ & $\begin{array}{c}5.0 \\
(2.5) \\
24\end{array}$ & $\begin{array}{c}4.6 \\
(2.2) \\
38\end{array}$ & $\begin{array}{c}5.1 \\
(2.7) \\
21\end{array}$ & $\begin{array}{c}5.0 \\
(3.2) \\
19\end{array}$ \\
\hline Hayling test & $\begin{array}{c}4.7 \\
(1.6) \\
36\end{array}$ & $\begin{array}{c}5.1 \\
(1.3) \\
11\end{array}$ & $\begin{array}{c}5.5 \\
(1.9) \\
16\end{array}$ & $\begin{array}{c}4.9 \\
(1.5) \\
38\end{array}$ & $\begin{array}{c}5.2 \\
(2.1) \\
22\end{array}$ & $\begin{array}{c}5.5 \\
(1.4) \\
25\end{array}$ & $\begin{array}{c}4.9 \\
(1.5) \\
38\end{array}$ & $\begin{array}{c}6.6 \\
(1.4) \\
19\end{array}$ & $\begin{array}{c}6.6 \\
(1.4) \\
18\end{array}$ \\
\hline $\begin{array}{l}\text { Social \& Occupational Functioning } \\
\text { Scale (averaged when } 2 \text { scores } \\
\text { available) }\end{array}$ & $\begin{array}{c}63.2 \\
(11.5) \\
35\end{array}$ & $\begin{array}{c}66.0 \\
(14.6) \\
20\end{array}$ & $\begin{array}{c}64.7 \\
(11.1) \\
19\end{array}$ & $\begin{array}{c}59.3 \\
(12.9) \\
34\end{array}$ & $\begin{array}{c}57.3 \\
(11.3) \\
29\end{array}$ & $\begin{array}{c}60.3 \\
(10.7) \\
28\end{array}$ & $\begin{array}{c}59.3 \\
(12.9) \\
34\end{array}$ & $\begin{array}{c}64.0 \\
(10.3) \\
17\end{array}$ & $\begin{array}{c}66.6 \\
(13.4) \\
18\end{array}$ \\
\hline $\begin{array}{l}\text { Days in hospital in } 9 \text { months post } \\
\text { randomisation } \\
\text { [Median; range] }\end{array}$ & & & $\begin{array}{c}6.4 \\
{[0]} \\
{[0-214]} \\
36\end{array}$ & & & $\begin{array}{c}13.9 \\
{[0]} \\
{[0-273]} \\
38\end{array}$ & & & \\
\hline Birchwood Insight Scale & $\begin{array}{c}8.6 \\
(3.0) \\
36\end{array}$ & $22^{(3.7)}$ & $\begin{array}{c}8.4 \\
(3.6) \\
22\end{array}$ & $\begin{array}{c}8.5 \\
38^{(3.4)}\end{array}$ & $29^{(3.4)}$ & $\begin{array}{c}8.2 \\
(3.6) \\
30\end{array}$ & $\begin{array}{c}8.5 \\
38^{(3.4)}\end{array}$ & $22^{(4.2)}$ & $19^{(3.1)}$ \\
\hline $\begin{array}{l}\text { Beliefs About Voices Questionnaire- } \\
\text { Revised (BAVQ-R); malevolence }\end{array}$ & $\begin{array}{c}9.1 \\
(5.5) \\
21\end{array}$ & $\begin{array}{c}7.5 \\
(5.7) \\
10\end{array}$ & $\begin{array}{c}8.8 \\
(5.3) \\
10\end{array}$ & $\begin{array}{c}9.8 \\
(6.5) \\
26\end{array}$ & $\begin{array}{c}8.8 \\
(6.6) \\
21\end{array}$ & $\begin{array}{c}9.4 \\
(6.7) \\
22\end{array}$ & $\begin{array}{c}9.8 \\
(6.5) \\
26\end{array}$ & $\begin{array}{c}7.7 \\
(7.2) \\
15\end{array}$ & $\begin{array}{c}6.2 \\
(6.4) \\
12\end{array}$ \\
\hline $\begin{array}{l}\text { BAVQ-R; } \\
\text { Omnipotence }\end{array}$ & $\begin{array}{c}9.6 \\
(4.2) \\
21\end{array}$ & $\begin{array}{c}8.6 \\
(3.7) \\
10\end{array}$ & $\begin{array}{c}7.7 \\
(4.2) \\
10\end{array}$ & $\begin{array}{c}11.3 \\
(4.8) \\
26\end{array}$ & $\begin{array}{c}8.4 \\
(6.5) \\
21\end{array}$ & $\begin{array}{c}9.7 \\
(5.7) \\
22\end{array}$ & $\begin{array}{c}11.3 \\
(4.8) \\
26\end{array}$ & $\begin{array}{c}8.2 \\
(4.6) \\
15\end{array}$ & $\begin{array}{c}6.1 \\
(4.9) \\
12\end{array}$ \\
\hline $\begin{array}{l}\text { BAVQ-R; } \\
\text { Resistance }\end{array}$ & $\begin{array}{c}18.3 \\
(5.9) \\
21\end{array}$ & $\begin{array}{c}16.6 \\
(7.3) \\
10\end{array}$ & $\begin{array}{c}18.4 \\
(6.3) \\
10\end{array}$ & $\begin{array}{c}18.2 \\
(6.6) \\
26\end{array}$ & $\begin{array}{c}18.1 \\
(8.4) \\
21\end{array}$ & $\begin{array}{c}17.1 \\
(8.2) \\
22\end{array}$ & $\begin{array}{c}18.2 \\
(6.6) \\
26\end{array}$ & $\begin{array}{c}15.1 \\
(7.5) \\
15\end{array}$ & $\begin{array}{c}14.7 \\
(8.1) \\
12\end{array}$ \\
\hline $\begin{array}{l}\text { Meta-Cognitions Questionnaire; } \\
\text { controllability of thoughts }\end{array}$ & $\begin{array}{c}44.0 \\
(11.0) \\
25\end{array}$ & $\begin{array}{c}36.7 \\
(10.4) \\
21\end{array}$ & $\begin{array}{c}39.6 \\
(8.9) \\
20\end{array}$ & $\begin{array}{c}44.0 \\
(14.2) \\
31\end{array}$ & $\begin{array}{c}45.8 \\
(14.6) \\
26\end{array}$ & $\begin{array}{c}40.2 \\
(14.2) \\
27\end{array}$ & $\begin{array}{c}44.0 \\
(14.2) \\
31\end{array}$ & $\begin{array}{c}45.8 \\
(11.2) \\
20\end{array}$ & $\begin{array}{c}40.3 \\
(14.5) \\
19\end{array}$ \\
\hline
\end{tabular}


Table 2. Number (\%) of patients using services, mean (sd) contacts by users and mean (sd) costs for whole sample.

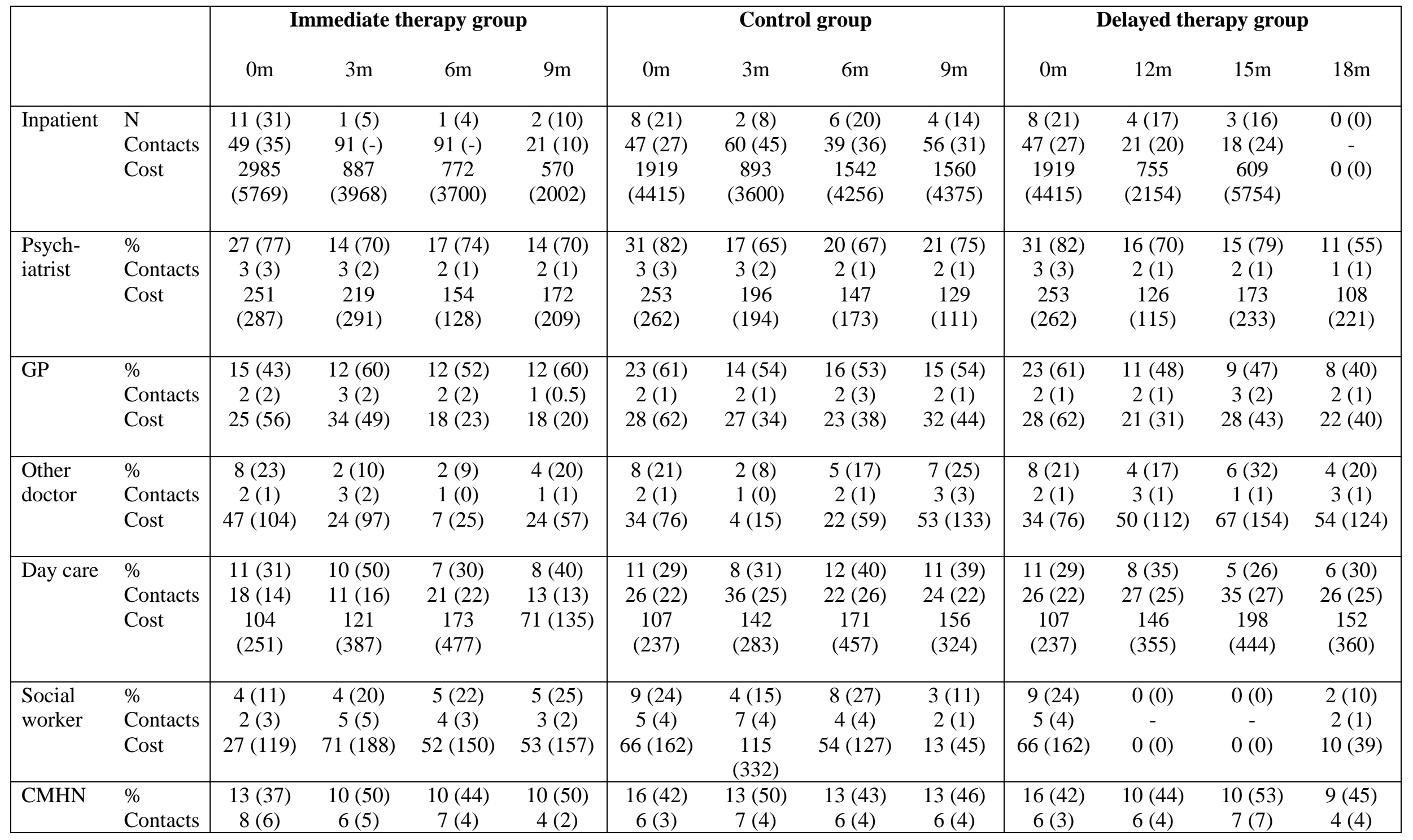




\begin{tabular}{|c|c|c|c|c|c|c|c|c|c|c|c|c|c|}
\hline & Cost & $\begin{array}{c}118 \\
(238)\end{array}$ & $\begin{array}{c}116 \\
(208)\end{array}$ & $\begin{array}{c}121 \\
(169)\end{array}$ & $59(77)$ & $92(162)$ & $\begin{array}{c}117 \\
(165)\end{array}$ & $\begin{array}{c}122 \\
(194)\end{array}$ & 83 (132) & $92(162)$ & $70(121)$ & $\begin{array}{c}118 \\
(212)\end{array}$ & 66 (119) \\
\hline Therapist & $\begin{array}{l}\% \\
\text { Contacts } \\
\text { Cost }\end{array}$ & $\begin{array}{c}5(14) \\
5(4) \\
35(124)\end{array}$ & $\begin{array}{c}0(0) \\
- \\
0(0)\end{array}$ & $\begin{array}{c}0(0) \\
- \\
0(0)\end{array}$ & $\begin{array}{c}4(20) \\
7(4) \\
99(253)\end{array}$ & $\begin{array}{c}2(5) \\
8(0) \\
22(97)\end{array}$ & $\begin{array}{c}1(4) \\
2(-) \\
2(11)\end{array}$ & $\begin{array}{c}1(3) \\
1(-) \\
2(11)\end{array}$ & $\begin{array}{c}1(4) \\
3(-) \\
6(33)\end{array}$ & $\begin{array}{c}2(5) \\
8(0) \\
22(97)\end{array}$ & $\begin{array}{c}1(4) \\
4(-) \\
10(48)\end{array}$ & $\begin{array}{c}1(5) \\
4(-) \\
11(47)\end{array}$ & $\begin{array}{c}1(5) \\
1(-) \\
3(13)\end{array}$ \\
\hline $\begin{array}{l}\text { Medic- } \\
\text { ation }\end{array}$ & $\begin{array}{l}\% \\
\text { Contacts } \\
\text { Cost }\end{array}$ & $\begin{array}{c}34(97) \\
- \\
427 \\
(306)\end{array}$ & $\begin{array}{c}19(95) \\
- \\
434 \\
(283)\end{array}$ & $\begin{array}{c}21(90) \\
- \\
409 \\
(307)\end{array}$ & $\begin{array}{c}18(94) \\
- \\
372 \\
(291)\end{array}$ & $\begin{array}{c}(90) \\
- \\
360 \\
(308)\end{array}$ & $\begin{array}{c}92 \\
- \\
378 \\
(304)\end{array}$ & $\begin{array}{c}90 \\
- \\
397 \\
(308)\end{array}$ & $\begin{array}{c}89 \\
- \\
365 \\
(284)\end{array}$ & $\begin{array}{c}(90) \\
- \\
360 \\
(308)\end{array}$ & $\begin{array}{c}83 \\
- \\
400 \\
(393)\end{array}$ & $\begin{array}{c}90 \\
- \\
485 \\
(391)\end{array}$ & $\begin{array}{c}80 \\
- \\
495 \\
(410)\end{array}$ \\
\hline $\begin{array}{l}\text { Informal } \\
\text { Care }\end{array}$ & $\begin{array}{l}\% \\
\text { Contacts } \\
\text { Cost }\end{array}$ & $\begin{array}{c}21(60) \\
8(12) \\
905 \\
(1955)\end{array}$ & $\begin{array}{c}13(65) \\
4(4) \\
589 \\
(706)\end{array}$ & $\begin{array}{c}13(57) \\
12(10) \\
1275 \\
(1798)\end{array}$ & $\begin{array}{c}13(65) \\
14(25) \\
1809 \\
(4062)\end{array}$ & $\begin{array}{c}18(47) \\
8(10) \\
780 \\
(1574)\end{array}$ & $\begin{array}{c}16(62) \\
9(10) \\
1111 \\
(1724)\end{array}$ & $\begin{array}{c}16(53) \\
8(10) \\
812 \\
(1545)\end{array}$ & $\begin{array}{c}18(64) \\
9(8) \\
1178 \\
(1503)\end{array}$ & $\begin{array}{c}18(47) \\
8(10) \\
780 \\
(1574)\end{array}$ & $\begin{array}{c}13(57) \\
9(10) \\
981 \\
(1687)\end{array}$ & $\begin{array}{c}14(74) \\
8(9) \\
1085 \\
(1643)\end{array}$ & $\begin{array}{c}14(70) \\
8(13) \\
1132 \\
(2300)\end{array}$ \\
\hline Other & $\begin{array}{l}\% \\
\text { Contacts } \\
\text { Cost }\end{array}$ & $\begin{array}{c}8(23) \\
6(12) \\
63(273)\end{array}$ & $\begin{array}{c}3(15) \\
2(1) \\
14(52)\end{array}$ & $\begin{array}{l}2(9) \\
1(0) \\
1(2)\end{array}$ & $\begin{array}{c}2(10) \\
5(2) \\
10(39)\end{array}$ & $\begin{array}{c}12(26) \\
10(14) \\
124 \\
(604)\end{array}$ & $\begin{array}{c}4(15) \\
11(17) \\
74(314)\end{array}$ & $\begin{array}{c}5(17) \\
21(25) \\
146 \\
(498)\end{array}$ & $\begin{array}{c}3(11) \\
14(9) \\
49(150)\end{array}$ & $\begin{array}{c}12(26) \\
10(14) \\
124 \\
(604)\end{array}$ & $\begin{array}{c}7(30) \\
16(14) \\
146 \\
(365)\end{array}$ & $\begin{array}{c}6(21) \\
10(3) \\
22(48)\end{array}$ & $\begin{array}{c}8(40) \\
8(8) \\
50(109)\end{array}$ \\
\hline Total & Cost & $\begin{array}{c}4988 \\
(5685)\end{array}$ & $\begin{array}{c}2509 \\
(3882)\end{array}$ & $\begin{array}{c}2980 \\
(3917)\end{array}$ & $\begin{array}{c}3257 \\
(4493)\end{array}$ & $\begin{array}{c}3786 \\
(5471)\end{array}$ & $\begin{array}{c}3059 \\
(4555)\end{array}$ & $\begin{array}{c}3438 \\
(4260)\end{array}$ & $\begin{array}{c}3626 \\
(5037)\end{array}$ & $\begin{array}{c}3786 \\
(5471)\end{array}$ & $\begin{array}{c}2705 \\
(3576)\end{array}$ & $\begin{array}{c}2796 \\
(3109)\end{array}$ & $\begin{array}{c}2091 \\
(2536)\end{array}$ \\
\hline
\end{tabular}


Figure 1 - CONSORT diagram 


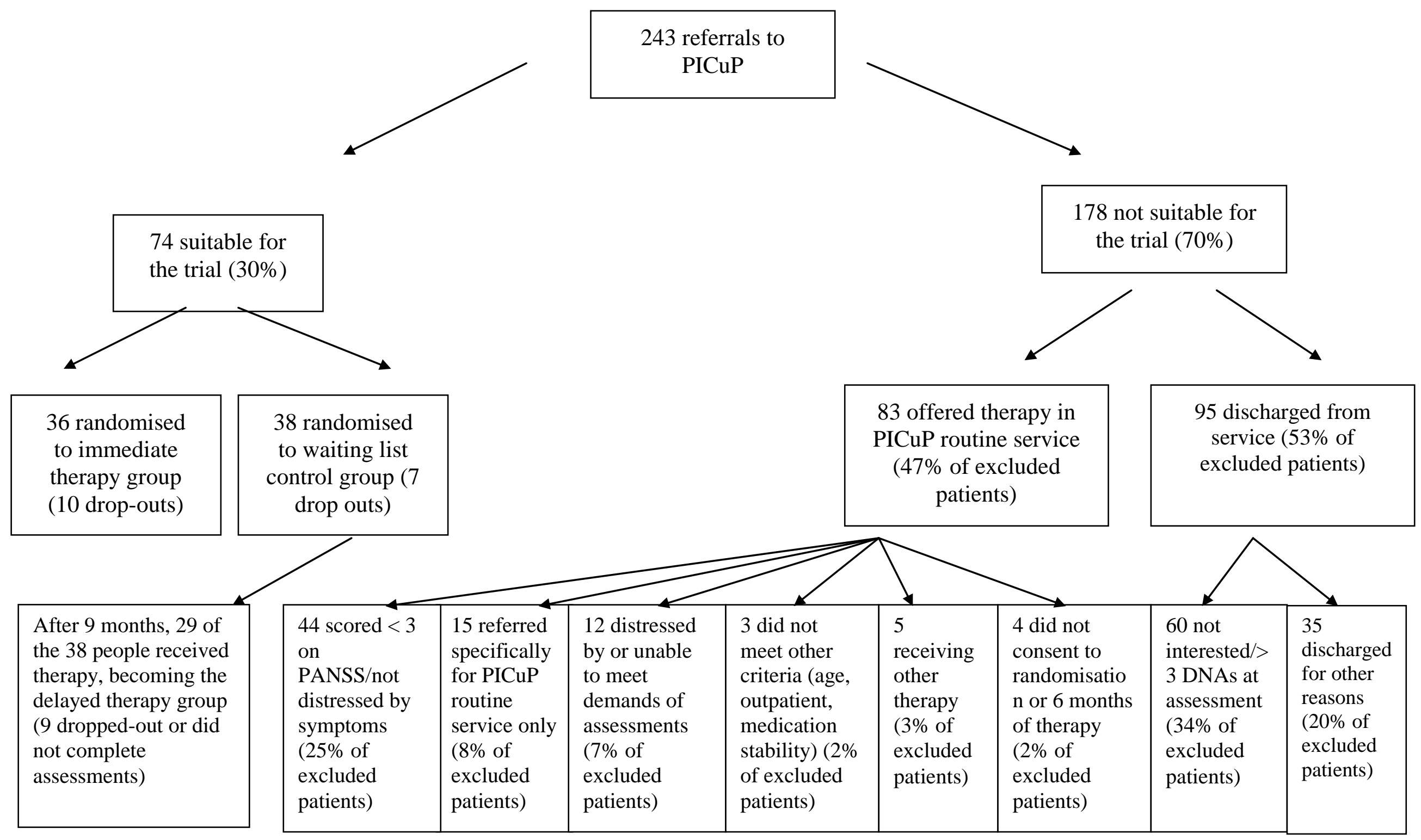


Figure 2: Variables where significant differences at end of therapy were not maintained at follow-up (showing average baseline values, estimated means, and available Ns)

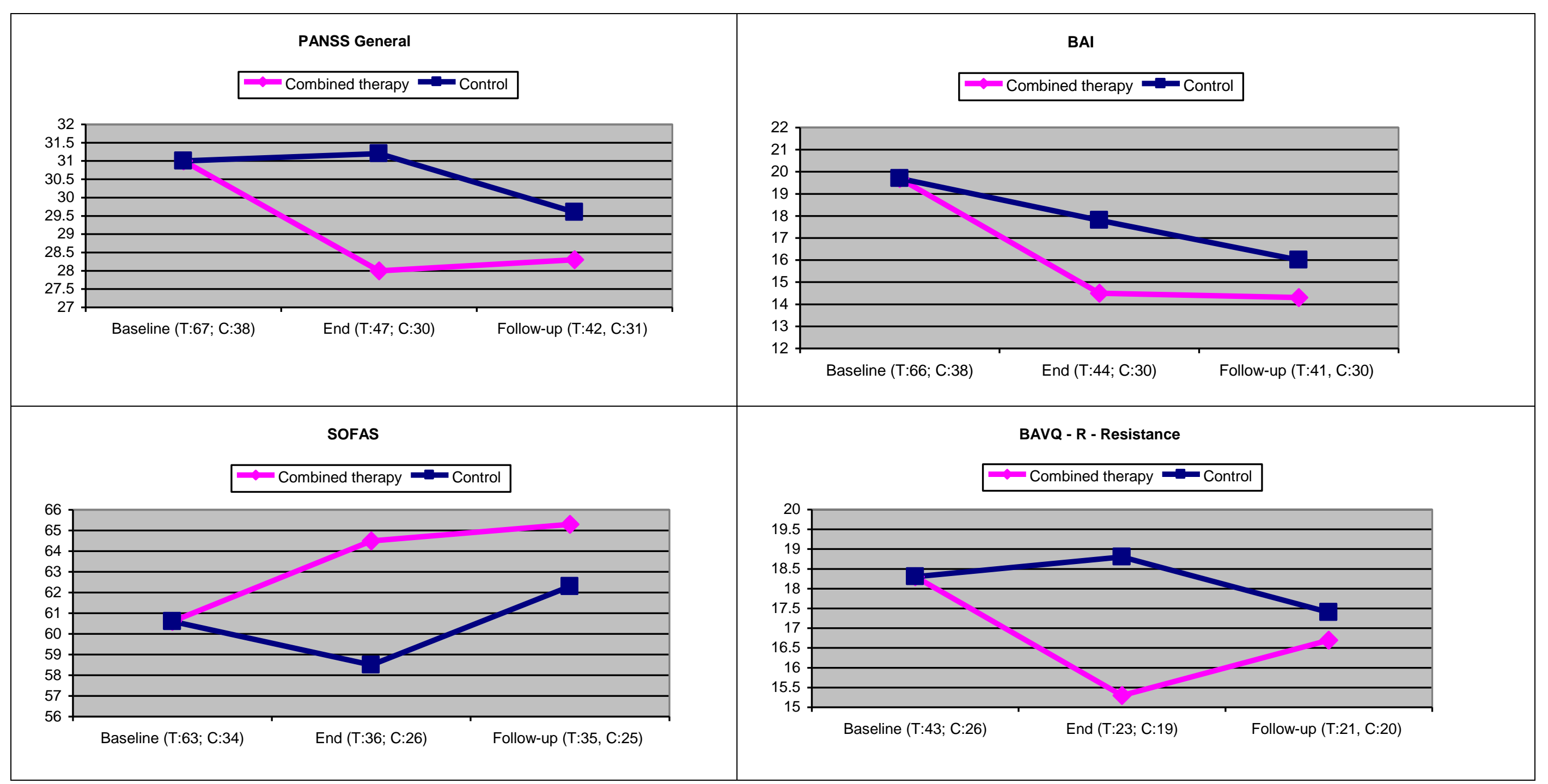

